\title{
Financial industry under the background of digital industry: A Bibliometric Analysis of Related Research
}

\author{
Chung-Lien Pan ${ }^{1, a^{*}}$, Xianghui Chen², Mei Lin², Zhuocheng $\mathrm{Cai}^{2}$, Xiaolin $\mathrm{Wu}^{2}$ \\ ${ }^{1}$ Nanfang College of Sun Yat-sen University, School of Accounting, Guangzhou, Guangdong \\ ${ }^{2}$ Nanfang College of Sun Yat-sen University, School of Accounting, Guangzhou, Guangdong
}

\begin{abstract}
In recent years, the innovation and breakthrough of digital technology have brought great convenience to the economic development of various sectors and People's daily life, especially in the field of financial services. To explore the impact of digital technology on the financial industry, this paper searched 285 papers based on Web of Science (WoS) and conducted a systematic scientific metrology and literature review, providing a research front for future research. According to the research papers published between 1984 and 2020, the analysis results of co-citation and co-cited by sources, disciplines, and keywords show that in recent years, the publishing industry in this field has developed rapidly in various countries, and the research field involves such disciplines as business economics, computer science, social science, and interdisciplinary application. According to the research papers published between 1984 and 2020, the analysis results of co-citation and co-cited by sources, disciplines, and keywords show that in recent years, the publishing industry in this field has developed rapidly in various countries, and the research field involves such disciplines as business, finance; economics; computer science; social science and interdisciplinary application. Besides, American, Chinese and British institutions are also good at hosting such interdisciplinary work. And different types of keywords present important interactions in the visualization: (a) digital-based innovation, (b) big data and regulation, (c) Internet finance and financial innovation, (d) financial inclusion, (e) digital finance and risk management, and (f) mobile payment.
\end{abstract}

\section{Introduction}

The rapid development of the digital economy at the national and global levels has accelerated the transformation process of the financial system and led to the financialization of the global economy [1]. The midterm report, "Harnessing Digitalization in Financing the Sustainable Development Goals", released by the United Nations Development Programme (UNDP) (2019), pointed out that it is hoped that the digital revolution can promote the leap-forward Development of the global financial ecosystem and realize the United Nations Sustainable Development Goals at an early date [2]. The combination of finance and information technology makes the traditional financial industry strongly influenced by digitalization. Fintech not only provides opportunities for creating new services and business models but also brings challenges to traditional financial service providers [3]. And bank as the IT technology and financial technology-intensive users, The article "Whose Customer You - The Reality of Digital Banking" (2018) published by The Economist, points out that the future of the banking industry is digital. Facing the technology and digital trend, Banks should improve the sensitivity of the industry and adapt to the development and

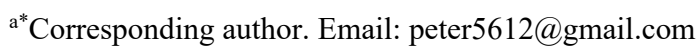

changes of related technologies as soon as possible [4]. "Digital transaction banking - Opportunities and challenges" (2015) published by Deloitte points out that with the advent of the digital era, the emergence of nonbanking institutions or financial technology enterprises has made Banks face greater challenges and have begun to change the face of the financial industry [5]. Not only that but with the rise of digital and electronic financial markets, new technologies are trying to translate newfound transparency into opportunities for financial monitoring and oversight [6]. "Technology power" will become the core competitive concept for the financial institutions of the future [7]. Among all kinds of insurance technology innovations in the insurance industry recently, medical insurance is one of the benefits of technological change $[8,9]$. It can be seen that digital technology is crucial to the development of the financial industry, and the application of financial digital technology has been a hot topic of discussion for many years.

Based on 285 articles collected by WoS, this paper conducts a scientific metrological analysis. The research trends; major countries; institutions; publications; and author keywords related to this subject are analyzed by visualization, which is aimed to fill the research gap by 
providing the latest scientific metrological analysis of the subject and providing directions for future research.

\section{DATA AND METHODS}

To discuss the impact of digital technology on the financial industry, we selected various literacy terms from the Oxford bibliography [10] and looked them up in the advanced search of network science:

$\mathrm{TS}=$ (financial technology OR Fintech OR fin-tech OR Digital finance* OR Internet finance* OR financial computing OR insurance Technology OR insurTech OR regulatory technolog* OR RegTech) $\mathrm{AND}(\mathrm{SU}=$ Business \& amp; Economics OR WC $=($ Business OR Business, Finance)).

By February 2020, a total of 285 articles (including sci-expanded SSCI) had been retrieved. And we use VOSviewer and Python visualization package to show this result.

\section{RESEARCH FINDINGS}

Our findings introduce the research trends, major countries; major institutions; major publications; and author keywords related to this subject.

\subsection{Annual trends}

The statistical data in figure 1 shows that since 2015, the number of publications on this topic has increased rapidly. At the same time, as can be seen from figure 2, since 2014, the rapid increase in the number of publication citations means that the popularity of topic papers has increased rapidly.

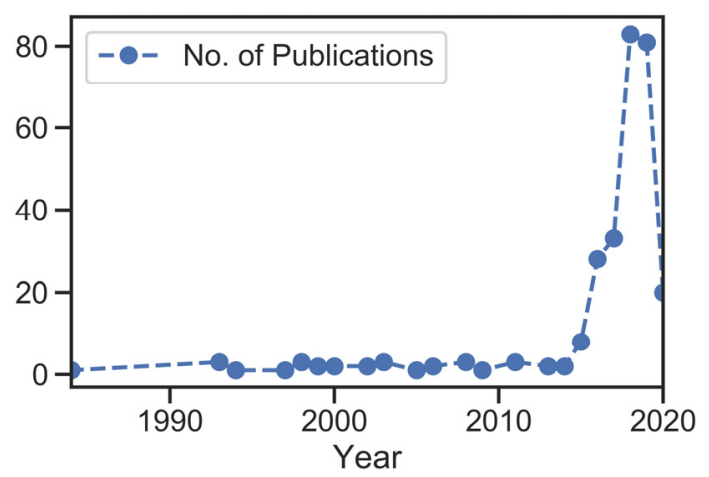

Figure1. The number of publications

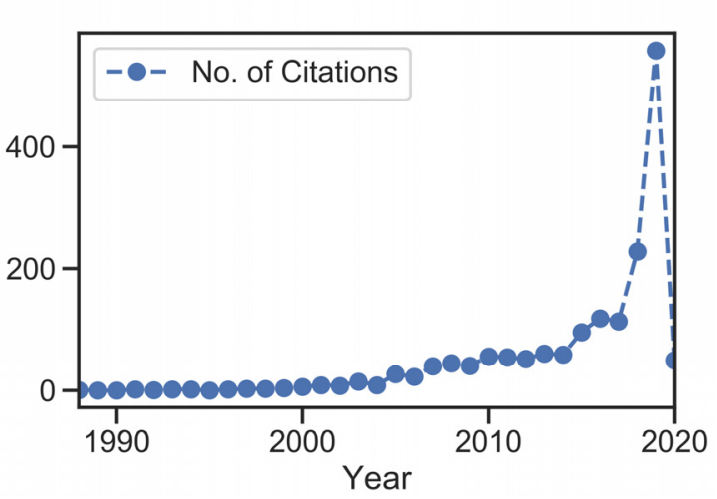

Figure2. The number of citations

\subsection{Major funding agencies}

From Table 1, we can find that the top three fund agencies are all from China, among which the national natural science foundation of China has the most funding for papers on this topic.

Table 1 MAJOR AGENCIES IN TOP 10

\begin{tabular}{|l|l|l|}
\hline Fund agencies & No. & \% \\
\hline $\begin{array}{l}\text { NATIONAL NATURAL SCIENCE } \\
\text { FOUNDATION OF CHINA }\end{array}$ & 22 & 7.719 \\
\hline MINISTRY OF EDUCATION CHINA & 3 & 1.053 \\
\hline $\begin{array}{l}\text { NATIONAL SOCIAL SCIENCE } \\
\text { FOUNDATION OF CHINA }\end{array}$ & 3 & 1.053 \\
\hline $\begin{array}{l}\text { SOCIAL SCIENCES AND } \\
\text { HUMANITIES RESEARCH COUNCIL } \\
\text { OF CANADA SSHRC }\end{array}$ & 3 & 1.053 \\
\hline ALTERUM & 2 & 0.702 \\
\hline ALTERUM GRANT & 2 & 0.702 \\
\hline AUSTRALIAN RESEARCH COUNCIL & 2 & 0.702 \\
\hline $\begin{array}{l}\text { CHINESE UNIVERSITY OF HONG } \\
\text { KONG }\end{array}$ & 2 & 0.702 \\
\hline $\begin{array}{l}\text { HONG KONG RESEARCH GRANTS } \\
\text { COUNCIL }\end{array}$ & 2 & 0.702 \\
\hline $\begin{array}{l}\text { MINISTRY OF EDUCATION OF THE } \\
\text { REPUBLIC OF KOREA }\end{array}$ & 2 & 0.702 \\
\hline
\end{tabular}

\subsection{Major countries and organizations}

Figure 3 and Figure 4 show the visual information of the bibliographical coupling network. Among them, the United States (74 articles in total) made the largest contribution and major organizations including Federal Reserve System USA.

State University System Of Florida; Massachusetts Institute Of Technology MIT; University Of Minnesota System. The second one is China (55 articles in total), the main agencies are Peking University, Zhejiang University Of Finance Economics. The third is the United Kingdom (31 articles in total), with major agencies including the University Of London and University Of New South Wales Sydney. But the leading 
institution in the center is Peking University from China, funding institutions in recent years. which is related to the strong support from mainland

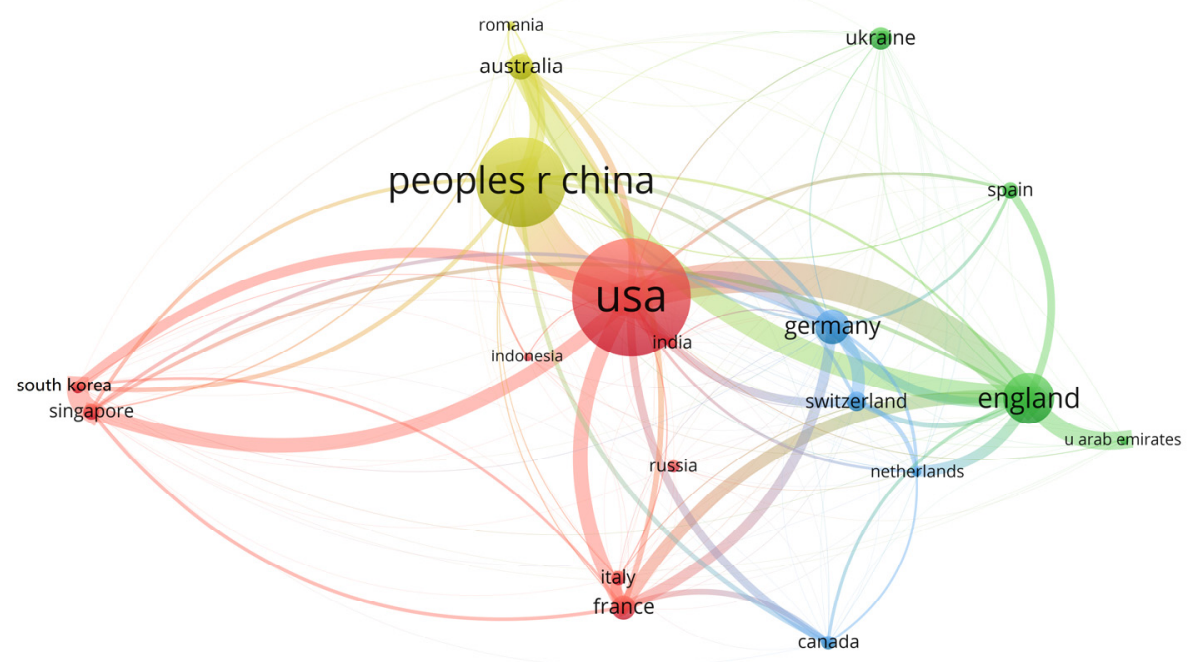

Figure3. Top 20 countries: a bibliographic coupling network visualization

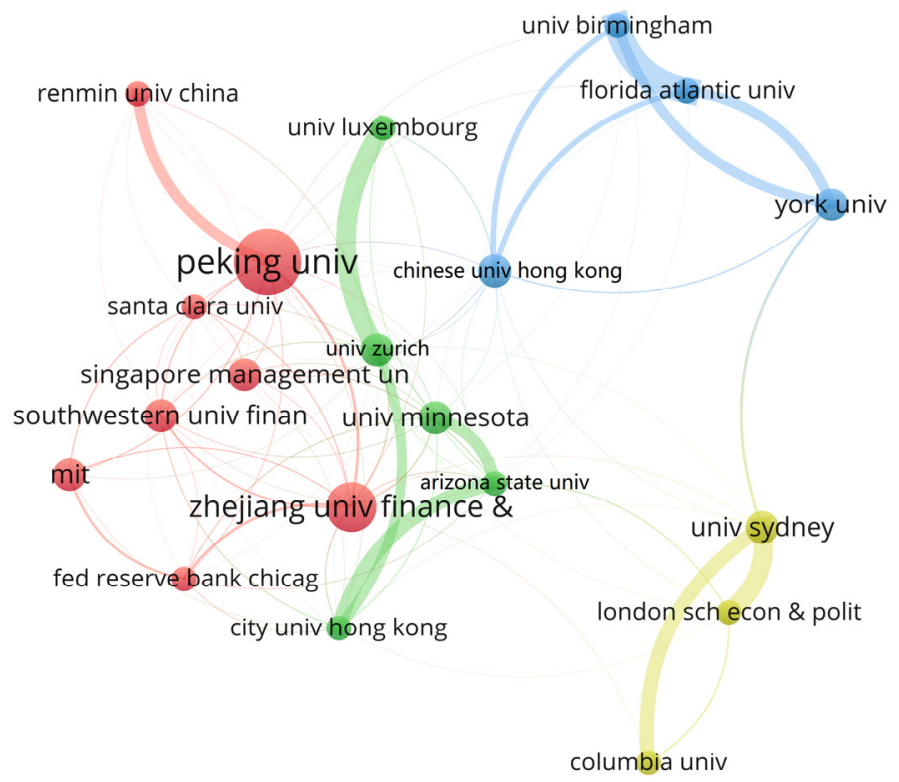

Figure4. Top 20 organizations: a bibliographic coupling network visualization

\subsection{Major publications}

Top 20 publications showed in figure5 reveal the interdisciplinary and multidisciplinary nature of digital technology research in the financial industry, covering related major disciplines, such as business; finance; economics; computer science; social science; and interdisciplinary application. Furthermore, the top 3 publication outlets are Electronic Commerce Research And Applications; Financial Innovation and Journal Of Management Information Systems. 


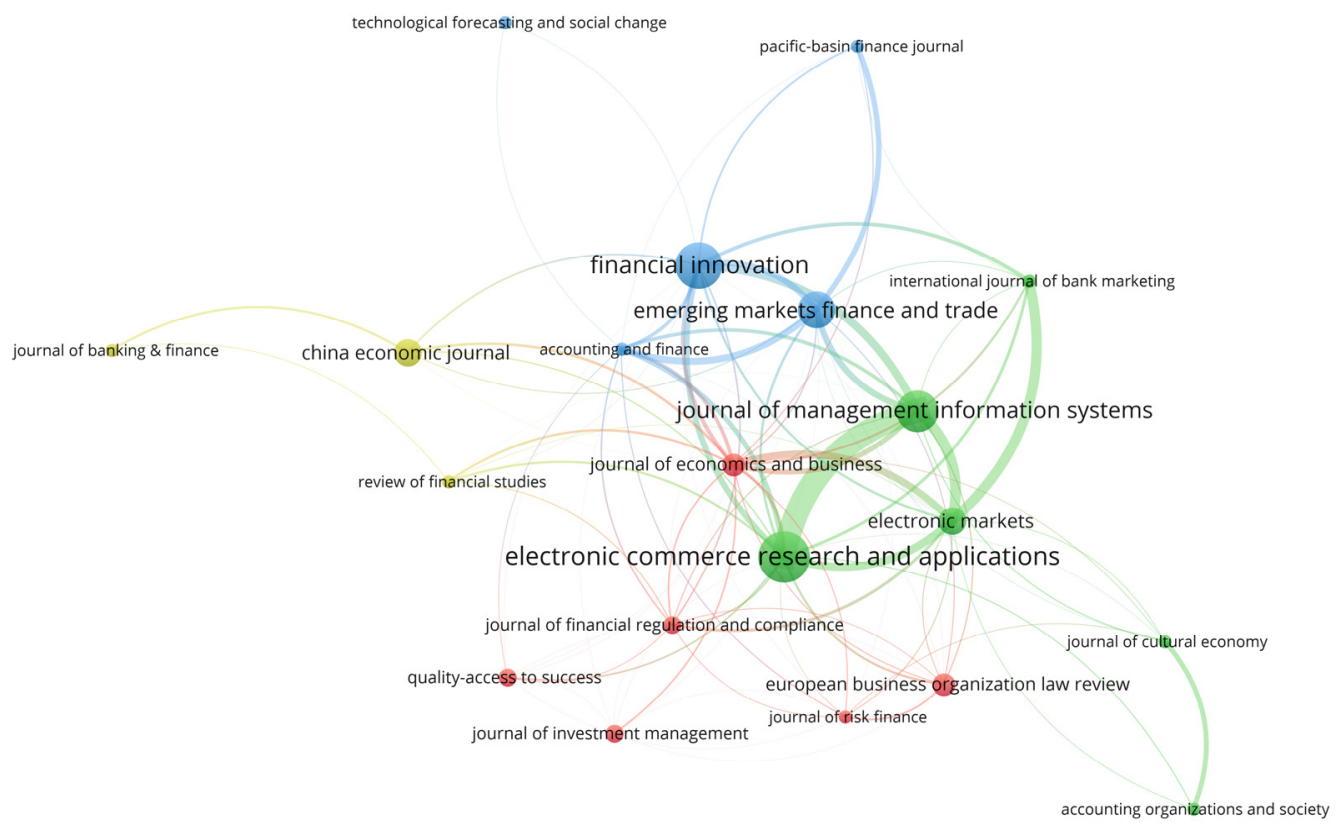

Figure5. Top 20 publication outlets: a bibliographic coupling network visualization

\subsection{Keyword co-occurrence network analysis}

To explore the correlation between keywords, the analysis of co-citation and co-cited was carried out in this paper. Figure6 shows the clustering results of the first 53 topics or concepts based on the co-occurrence of author keywords.

The first set of the largest cluster (red) based on digital-based innovation keywords mainly focuses on financial technology; blockchain; cryptocurrency; regulation technology; digitalization; financial services and business models [11]. Among the innovative business models, the category of fintech is the most active and has completely changed the landscape of the existing financial industry. Cryptocurrencies born from the application of blockchain technology, such as bitcoin, have attracted a large number of investors in recent years, with an amazing growth rate.

Second cluster (purple) based on big data and regulation keywords mainly focus on $\mathrm{p} 2 \mathrm{p}$ lending; soft information; social media; shadow banking, which mainly discuss the lending market regulatory issues $[12,13,14]$. The emergence of $p 2 p$ lending platforms has solved the problem of fund borrowing for many low and middle-income people, but also resulted to many unliquidated debts and even the absconding of platform operators. Therefore, strengthening supervision has become an important issue at this stage.

Third cluster (green) based on Internet finance and financial innovation mainly focus on crowdfunding, equity crowdfunding, information asymmetry, entrepreneurship, which mainly discussing issues related to the new method of enterprise financing [15] Both crowdfunding and equity-based crowdfunding are emerging financing methods, which enable entrepreneurs with dreams or aspirations to complete their plans through crowdfunding platforms and gather the strength of small groups, instead of relying on loans from financial institutions.

Fourth cluster (yellow) mainly focuses on financial inclusion [16]; innovation financialization and technology.

Fifth cluster (blue) based on digital finance and risk management is mainly focused on artificial intelligence; machine learning; financial institutions; China. By using a lot of artificial intelligence and machine learning to serve the financial industry, digital finance must also be coupled with appropriate risk control mechanisms.

sixth cluster (orange) mainly focuses on mobile payment emerging markets and mobile banking. 


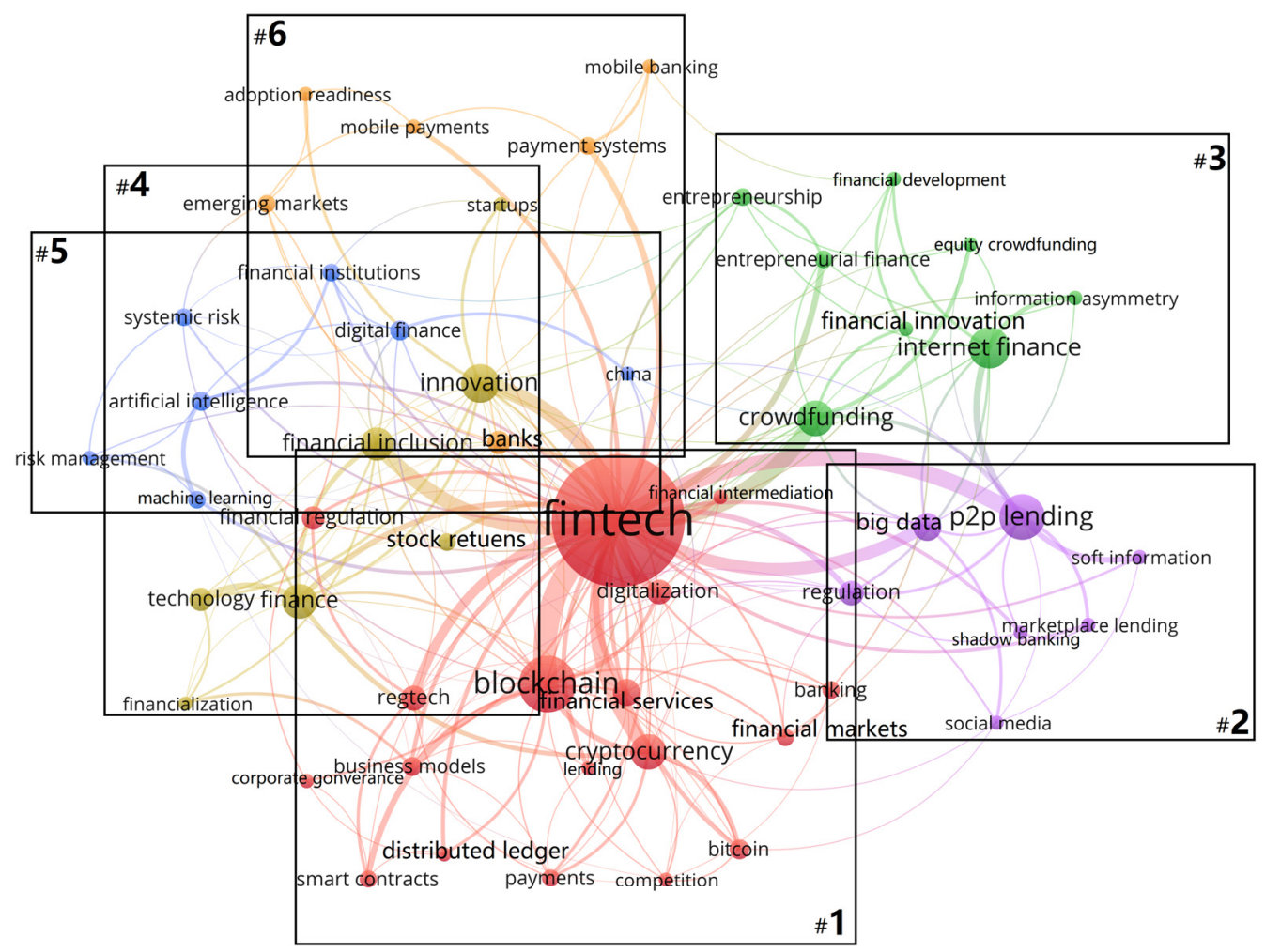

Figure6. Map based on author's keyword co-occurrence network: visualization of clustering results

\section{CONCLUSION}

The important conclusions of this paper are as follows:

1) The number of publications in this field has increased rapidly, triggering a research boom since 2015;

2) The largest contributors to the research are the United States, China, and the United Kingdom, moreover, the top three fund agencies are all from China;

3) Top publication sources reveal the interdisciplinary and multidisciplinary nature of digital technology research in the financial industry;

4) Main research contents include: (a) digital-based innovation,(b) big data and regulation,(c) Internet finance and financial innovation,(d) financial inclusion, (e) digital finance and risk management, and $(f)$ mobile payment.

Generally, the development of digital financial technology plays a multifaceted and multi-level role in the financial field. Its influence has extended to every aspect of modern people's work and life, formally announcing the arrival of the digital age. And the research in this field will also present a situation of blooming flowers, which is worthy of our attention.

\section{References}

1. Zveryakov, M., Kovalenko, V., Sheludko, S., \& Sharah, E, (2019). FinTech sector and banking business: competition or symbiosis?.

2. United Nations Development Programme (UNDP). Task Force on Digital Financing of the Sustainable Development Goals.(2019). Report of Harnessing Digitalization in Financing of the Sustainable Development Goals. Retrieved from: https://digitalfinancingtaskforce.org/wpcontent/uploads/2019/09/Task-Force-CoChairInterim-Report.pdf

3. Zavolokina, L., Dolata, M., \& Schwabe,. G. (2016). The FinTech phenomenon: antecedents of financial innovation perceived by the popular press. Financial Innovation, 2(1), 1-16.

4. Renée Friedman.(2018). The Economist IU-Whose Customer Are You-The Reality of Digital Banking. Retrieved from: https://perspectives.eiu.com/financialservices/whose-customer-are-you-reality-digitalbanking

5. Mohit Mehrotra (2015).Digital transaction bankingOpportunities and challenges. Retrieved from: https://www2.deloitte.com/tl/en/pages/financialservices/articles/digital-transaction-bankingopportunities-challenges.html 
6. Williams, J. W. (2009). Envisioning financial disorder: Financial surveillance and the securities industry. Economy and Society, 38(3), 460-491.

7. Chen, Z., Li, Y., Wu, Y., \& Luo, J. (2017). The transition from traditional banking to mobile internet finance: an organizational innovation perspective-a comparative study of Citibank and ICBC. Financial Innovation, 3(1), 1-16.

8. Stoeckli, E., Dremel, C., \& Uebernickel, F. (2018). Exploring characteristics and transformational capabilities of InsurTech innovations to understand insurance value creation in a digital world. Electronic Markets, 28(3), 287-305.

9. Goddeeris, J. H. (1984). Medical insurance, technological change, and welfare. Economic Inquiry, 22(1), 56-67.

10. Anon Digital Literacy - Communication - Oxford Bibliographies - obo.

11. Gomber, P., Kauffman, R. J., Parker, C., \& Weber, B. W. (2018). On the fintech revolution: interpreting the forces of innovation, disruption, and transformation in financial services. Journal of Management Information Systems, 35(1), 220-265.
12. Yan, J., Yu, W., \& Zhao, J. L. (2015). How signaling and search costs affect information asymmetry in P2P lending: the economics of big data. Financial Innovation, 1(1), 19.

13. Buchak, G., Matvos, G., Piskorski, T., \& Seru, A. (2018). Fintech, regulatory arbitrage, and the rise of shadow banks. Journal of Financial Economics, 130(3), 453-483.

14. Ge, R., Feng, J., Gu, B., \& Zhang, P. (2017). Predicting and deterring default with social media information in peer-to-peer lending. Journal of Management Information Systems, 34(2), 401-424.

15. Ahlstrom, D., Cumming, D. J., \& Vismara, S. (2018). New methods of entrepreneurial firm financing: Fintech, crowdfunding and corporate governance implications. Corporate Governance: An International Review, 26(5), 310-313.

16. Gabor, D., \& Brooks, S. (2017). The digital revolution in financial inclusion: international development in the fintech era. New Political Economy, 22(4), 423-436. 